\title{
Commentary: Simple math is not so straightforward with stereotactic body radiotherapy for colorectal carcinoma metastases
}

\author{
W. Hampton Gray, MD, Scott M. Atay, MD, and Anthony W. Kim, MD
}

\footnotetext{
From the Division of Thoracic Surgery, Keck School of Medicine of the University of Southern California, Los Angeles, Calif.

Disclosures: Authors have nothing to disclose with regard to commercial support.

Received for publication March 26, 2019; accepted for publication March 26, 2019; available ahead of print May $14,2019$.

Address for reprints: Anthony W. Kim, MD, Division of Thoracic Surgery, Keck School of Medicine, University of Southern California, Los Angeles, CA 90033 (E-mail: anthony.kim@med.usc.edu).

J Thorac Cardiovasc Surg 2019;158:1242-3

$0022-5223 / \$ 36.00$

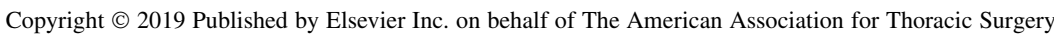
https://doi.org/10.1016/j.jtcvs.2019.03.063
}

For more than a decade stereotactic body radiation therapy (SBRT) has been used with increasing frequency to treat early stage lung cancer as an alternative to surgical resection. ${ }^{1}$ Early successes with SBRT in early stage lung cancer rendered it as being the equivalent to a nonanatomic wedge resection. ${ }^{2}$ On the whole, subsequent studies have yet to move the proverbial SBRT needle beyond this point. ${ }^{1,3,4}$ Nevertheless, modest successes in this space has driven consideration for expanded indications including pulmonary metastases. Unique to metastases and unlike primary lung malignancies, when feasible, wedge resection is considered the standard surgical resection. The term "standard" must be interpreted in context because metastasectomy is presumed to augment survival by achieving local disease control despite being used to treat the clinical manifestation of an ostensibly systemic problem. Wedge resection for colorectal carcinoma metastatic to the lung is no exception. Therefore, it is logical by way of the transitive property to reason that if SBRT is equivalent to a wedge resection and wedge resection is considered the preferred approach for colorectal pulmonary metastases, then SBRT could serve as an equivalent alternative.

In this issue of The Journal of Thoracic and Cardiovascular Surgery, Nelson and colleagues report the results of their retrospective study on a 10-year experience with local recurrence after either surgical wedge resection or SBRT for patients with pulmonary metastasis from colorectal carcinoma. ${ }^{5}$ There were 381 patients who had definitive therapy for 826 pulmonary nodules with a median follow-up of 4 years. Statistical analysis included an unweighted cohort, a propensity matched cohort, and an exploratory analysis using matching weights on the "favorable" subgroup $(<3 \mathrm{~cm})$. A larger tumor size and receipt of SBRT were associated with an increased risk of local recurrence (hazard ratio, 1.38 and 3.28, respectively) in the unweighted cohort. Analysis of the curve.

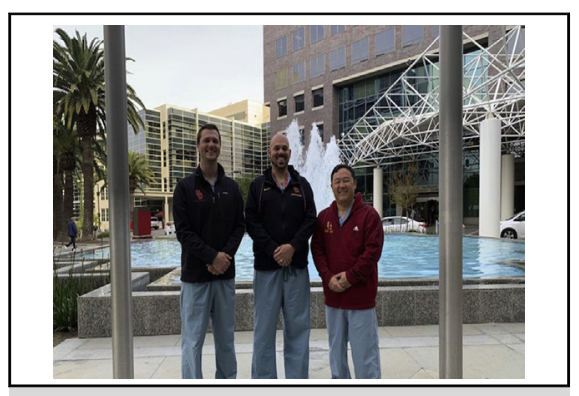

W. Hampton Gray, MD, Scott M. Atay, MD, and Anthony W. Kim, MD

Central Message

Surgical resection for colorectal pulmonary metastasis offers superior local control compared with SBRT.

See Article page 1234.

propensity matched groups continued to show an increase in local recurrence rate for SBRT compared with wedge resection at 2 years $(29.4 \%$ vs $14.1 \%)$ and at 5 years $(37.3 \%$ vs $18.4 \%)$, respectively. The authors conclude that surgical wedge resection is associated with lower rates of local failure compared with SBRT for the treatment of colorectal pulmonary metastases.

Although deciding between surgery or SBRT might be complex because of the challenges of determining fitness for the former, the findings of Nelson and colleagues support that the benefit of surgery over SBRT is not the complex component of the equation. Despite these findings, it is undeniable that SBRT has positively changed the landscape for patients with all types of lung malignancies. In many cases, patients who would otherwise go untreated or undertreated, curative intent therapy is now available. Studies such as this one provide contextual insight regarding the utilization of therapies other than surgery. In this regard, one of the more remarkable aspects of this study that bears noting is that the use of SBRT for metastatic lesions occurred during a period when most institutions were using it exclusively in patients with primary lung cancer. The authors should be lauded for thinking ahead of the

As surgeons we might believe the results of this study justify our continued existence, but we would be wise to 
not rest easy. A local recurrence rate of nearly $20 \%$ for margin-negative resections is still high and suggests that further refinements are required in our own approach to metastatic colorectal carcinoma. Furthermore, as the authors note, local failure overlapped with distant failure, such that the management of pulmonary metastases was no longer a relevant outcome. With the limited morbidity of SBRT, perhaps a local recurrence is not so bad. Until we gain a better understanding of the multifaceted aspects of addressing colorectal carcinoma metastases to the lung, surgical resection remains the gold standard for now, but perhaps will not be our final answer to this problem.

\section{References}

1. Chang JY, Senan S, Paul MA, Mehran RJ, Louie AV, Balter P, et al. Stereotactic ablative radiotherapy versus lobectomy for operable stage I non-small-cell lung cancer: a pooled analysis of two randomised trials. Lancet Oncol. 2015;16:630-7.

2. Timmerman RD, Paulus R, Pass HI, Gore EM, Edelman MJ, Galvin J, et al. Stereotactic body radiation therapy for operable early-stage lung cancer: findings from the NRG Oncology RTOG 0618 trial. JAMA Oncol. 2018;4:1263-6.

3. Rosen JE, Salazar MC, Wang Z, Yu JB, Decker RH, Kim AW, et al. Lobectomy versus stereotactic body radiotherapy in healthy patients with stage I lung cancer. J Thorac Cardiovasc Surg. 2016;152:44-54.

4. Crabtree TD, Denlinger CE, Meyers BF, El Naqa I, Zoole J, Krupnick AS, et al. Stereotactic body radiation therapy versus surgical resection for stage I nonsmall cell lung cancer. J Thorac Cardiovasc Surg. 2010;140:377-86.

5. Nelson DB, Tayob N, Nguyen Q-N, Erasmus J, Mitchell KG, Hofstetter WL, et al. Local failure after stereotactic body radiation therapy or wedge resection for colorectal pulmonary metastases. J Thorac Cardiovasc Surg. 2019;158:1234-41.e16. 